BRE 10313

\title{
Diazepam and its Anomalous $p$-Chloro-derivative Ro 5-4864: Comparative Effects on Mouse Neurons in Cell Culture
}

\author{
JOHN H. SKERRITT, MARY ANN WERZ, MICHAEL J. MCLEAN and ROBERT L. MACDONALD \\ Department of Neurology, University of Michigan Medical Center, Ann Arbor, MI 48109 (U.S.A.)
}

(Accepted February 21st, 1984)

Key words: Ro 5-4864 - diazepam - benzodiazepine receptors - cultured neurons - gamma-aminobutyric acid convulsants - anticonvulsants

\begin{abstract}
The actions of diazepam and its p-chloro-derivative Ro 5-4864 were compared on mouse spinal cord and dorsal root ganglion neurons in cell culture. Diazepam enhanced but Ro 5-4864 reduced iontophoretic GABA responses in a concentration-dependent manner. Both diazepam and Ro 5-4864 limited sustained, high frequency repetitive firing of spinal cord neurons but diazepam was more potent. Ro 5-4864 was, however, more potent than diazepam in inhibiting spontaneous neuronal activity of spinal cord neurons and reducing the duration of calcium-dependent action potentials of dorsal root ganglion neurons. The differing actions of diazepam and Ro 5-4864 may account for the contrasting pharmacological spectra of the two benzodiazepines.
\end{abstract}

\section{INTRODUCTION}

Benzodiazepines such as diazepam have a range of clinically useful effects including anxiolytic, anticonvulsant, muscle relaxant and sedative-hypnotic actions $^{9}$. However, modifications of the benzodiazepine structure have been made in an attempt to develop benzodiazepines with a narrower, more selective spectrum of activity. One such benzodiazepine is Ro 5-4864 (7-chloro-1,3-dihydro-1-methyl-5-( $p$ chlorophenyl)-2H-1,4-benzodiazepine-2-one), the 4 '-chloro-derivative of diazepam ${ }^{36}$. In the mid 1960's this compound aroused interest because its anticonvulsant profile against experimental seizures in mice was unique for a benzodiazepine ${ }^{36}$. Virtually all benzodiazepines, including diazepam, had been shown to have potent anticonvulsant activity against pentylenetetrazol (PTZ) seizures and less potent activity against maximal electroshock (MES) seizures. In contrast, Ro 5-4864 had potent anti-MES seizure activity but was virtually inactive against PTZ seizures. Ro 5-4864 and diazepam also have been shown to have rather different behavioral profiles ${ }^{5-7,25}$, although they both were shown to have sedative ac- tions ${ }^{6,25,36}$. Interest in Ro 5-4864 waned, however, as further studies in mice revealed that the compound had a paradoxical convulsant activity36. Furthermore, the anti-MES seizure activity could not be confirmed in some studies ${ }^{24,36}$.

The bases for the different effects of diazepam and Ro 5-4864 are unclear. Diazepam and other anxiolytic or anticonvulsant benzodiazepines have been shown to enhance GABA responses ${ }^{3,9,17}$, presumably by binding to high affinity benzodiazepine receptors and to have no effect on glutamate responses ${ }^{15}$. Ro 5-4864, however, only very weakly interacts with high affinity benzodiazepine binding sites $^{33}$. Specific binding sites in the brain, spinal cord and peripheral tissues have been reported for $\left[{ }^{3} \mathrm{H}\right] \mathrm{Ro}$ 5-4864 (refs. 4, 21, 27, 28 and 32), but these sites have marked pharmacological and thermodynamic differences from 'classical' benzodiazepine receptors ${ }^{28,32}$. Thus, it is likely that diazepam and Ro 5-4864 have different actions on GABAergic inhibition.

To understand more completely the mechanisms of action of 'classical' and atypical benzodiazepines, we have investigated the actions of Ro 5-4864 and diazepam upon mouse spinal cord and dorsal root gan-

Correspondence: R. L. Macdonald, Neuroscience Laboratory Building, 1103 East Huron, Ann Arbor, 48109, U.S.A. 
glion neurons in cell culture. First, we have compared the actions of diazepam and Ro 5-4864 on GABA and glutamate responses evoked on spinal cord neurons. Second, we have investigated the action of the benzodiazepines on sustained, high frequency repetitive firing in spinal cord neurons. We have previously shown that several anticonvulsants which are also effective against MES seizures, including phenytoin and carbamazepine, reduced sustained high frequency repetitive firing $14,19,20$. Finally, we have studied the effects of diazepam and Ro 5-4864 on spontaneous activity and calcium-dependent action potential duration. We have shown that reduction of spontaneous activity and calcium-dependent action potential duration by anticonvulsants, including phenobarbital and phenytoin, correlates with reduction of presynaptic calcium uptake and reduction of synaptic transmission and may be a sedative/ anesthetic action ${ }^{10,14}$.

\section{MATERIAL AND METHODS}

Spinal cords with attched dorsal root ganglia were dissected from 12-14 day old mouse embryos and dissociated to a cell suspension. The spinal cord and dorsal root ganglion neurons were then maintained in cell culture as earlier described ${ }^{26}$. Neurons (5-8 weeks in vitro) were penetrated under visual guidance on the modified stage of an inverted phasecontrast microscope with high impedance (25-50 $\mathrm{M} \Omega$ ) glass micropipettes. Using a conventional bridge circuit, simultaneous current injection and membrane potential measurement were possible with a single micropipette. Spinal cord and dorsal root ganglion neurons could be identified unambiguously by visual and electrophysiological criteria ${ }^{26}$. Data were recorded on a Gould (2600S) polygraph or by filming of oscilloscope records. For assessment of spontaneous neuronal activity, repetitive firing and responses to iontophoretically applied S-glutamate, recording micropipettes were filled with $4 \mathrm{M}$ potassium acetate (KAc). Three $\mathrm{M}$ potassium chloride $(\mathrm{KCl})$ filled micropipettes were used to study GABA responses, while $4 \mathrm{M}$ cesium acetate (CsAc) filled micropipettes were used to study calcium-dependent action potentials. In most experiments a Dulbecco's phosphate buffered saline was used as the recording medium $\left(\mathrm{NaCl} 143.4 \mathrm{mM}, \mathrm{KCl} 4.2 \mathrm{mM}, \mathrm{CaCl}_{2} 0.9\right.$
$\mathrm{mM}, \mathrm{MgCl}_{2} 0.9 \mathrm{mM}$ and glucose $5.6 \mathrm{mM}$ in $9.5 \mathrm{mM}$ sodium phosphate buffer, $\mathrm{pH}$ 7.35-7.40). For studies of amino acid responses or repetitive firing, background spontaneous activity was suppressed by elevation of the magnesium ion concentration to 10 $\mathrm{mM}$. For calcium-dependent action potential studies, a $13 \mathrm{mM}$ Tris buffer containing $\mathrm{NaCl} 137.0 \mathrm{mM}, \mathrm{KCl}$ $5.3 \mathrm{mM}, \mathrm{CaCl}_{2} 5.0 \mathrm{mM}, \mathrm{MgCl}_{2} 0.8 \mathrm{mM}$, tetraethylammonium (TEA) chloride $5.0 \mathrm{mM}$ and $5.6 \mathrm{mM}$ glucose, at $\mathrm{pH} 7.30$, was used. Amino acid and calciumdependent action potential experiments were performed at $33-34{ }^{\circ} \mathrm{C}$, while spontaneous activity and repetitive firing experiments were performed at $36-37^{\circ} \mathrm{C}$.

Depolarizing steps of $450 \mathrm{~ms}$ duration were used to elicit repetitive firing in spinal cord neurons; drugs were bath applied following the demonstration of sustained repetitive firing in at least 3 control cells in each culture studied. Spontaneous activity in neuronal populations was determined over a $3 \mathrm{~min}$ period in each cell and was graded according to the arbitrary 5 point scale shown in Fig. 5 (see ref. 18 for more detailed explanation). For iontophoresis, GABA (0.5 $\mathrm{M}$, pH 3.2) or S-glutamate $(0.5 \mathrm{M}, \mathrm{pH} 10.0)$ were applied using $400 \mathrm{~ms}$ duration rectangular current pulses (GABA up to $+20 \mathrm{nA}$, S-glutamate up to -60 $\mathrm{nA})$ at $4 \mathrm{~s}$ intervals. Benzodiazepines or vehicle $(0.1 \%$ or less dimethylsulfoxide) were simultaneously applied by miniperfusion $(0.2$ psi ejection pressure, $30 \mathrm{~s}$ pulses) from a blunt tipped $(5-10 \mu \mathrm{m})$ micropipette positioned $15-50 \mu \mathrm{m}$ from the soma of the cell under study. Vehicle alone did not alter amino acid responses, repetitive firing, or action potential duration. Since dimethylsulfoxide weakly suppressed spontaneous activity, paired concentration vehicle controls were run in all experiments. Iontophoretic currents were adjusted to obtain amino acid responses of 6-9 $\mathrm{mV}$ amplitude, and data were accepted only if the responses returned to control amplitude within $5 \mathrm{~min}$ of removal of the benzodiazepine-containing micropipette.

In some experiments the interaction between benzodiazepines and the benzodiazepine antagonist Ro 15-178811 was investigated. Ro 15-1788 was applied by diffusion from large tipped $(10-20 \mu \mathrm{m})$ micropipettes, diazepam and Ro 5-4864 by miniperfusion, and GABA by iontophoresis. After a diazepam or Ro 5-4864 effect was obtained on a GABA response, 
A1. GABA PRE

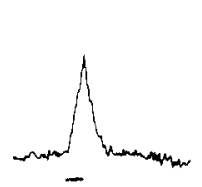

DIAZ

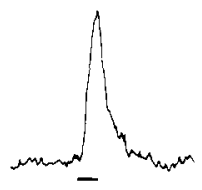

POST

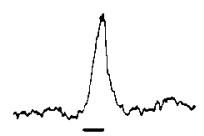

B1. GABA

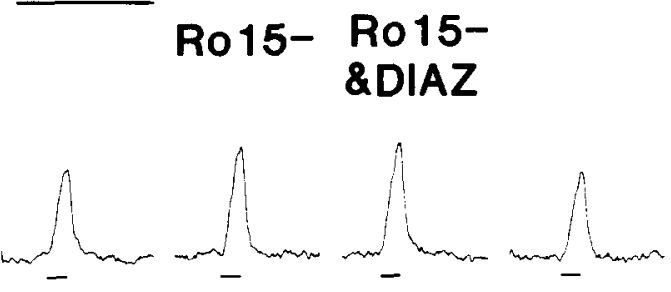

C1. GLU

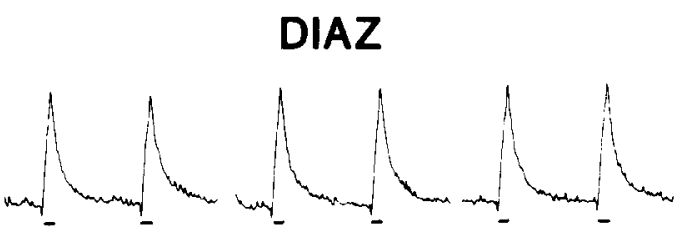

A2. GABA

PRE Ro5-4864 POST
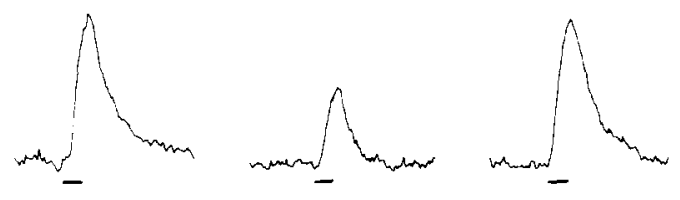

B2. GABA
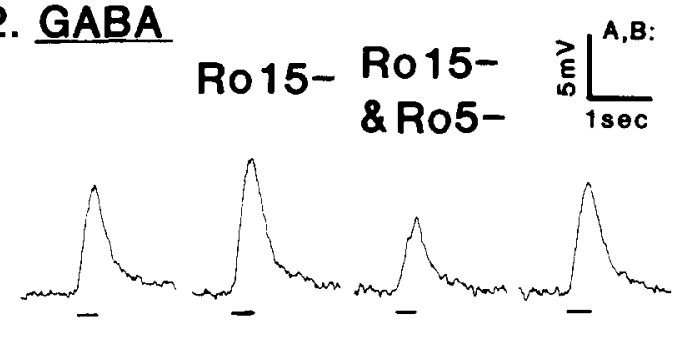

C2. GLU

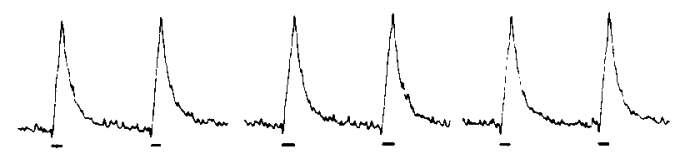

Fig. 1. A: differing effects of diazepam $(100 \mathrm{nM}, \mathrm{A} 1$, membrane potential, $\mathrm{MP}=-82 \mathrm{mV})$ and $\mathrm{Ro} 5-4864(10 \mu \mathrm{M}, \mathrm{A} 2, \mathrm{MP}=-83 \mathrm{mV})$ on GABA responses of spinal cord neurons. B: Ro 15-1788 $(1 \mu \mathrm{M})$ weakly enhanced GABA responses and blocked further enhancement by $100 \mathrm{nM}$ diazepam $(\mathrm{B} 1, \mathrm{MP}=-75 \mathrm{mV})$ while failing to alter inhibition by $10 \mu \mathrm{M}$ Ro $5-4864(\mathrm{~B} 2, \mathrm{MP}=-80 \mathrm{mV})$. C: glutamate responses were unaltered by $1 \mu \mathrm{M}$ diazepam $(\mathrm{C} 1, \mathrm{MP}=-71 \mathrm{mV})$ or by $10 \mu \mathrm{M}$ Ro 5-4864 $(\mathrm{C} 2, \mathrm{MP}=-60 \mathrm{mV})$. Recordings were with $3 \mathrm{M} \mathrm{KCl}$-filled micropipettes. Time of amino acid application is indicated by horizontal bars below amino acid responses.

a micropipette containing Ro 15-1788 was positioned near $(20-50 \mu \mathrm{m})$ the tip of the GABA pipette. Diazepam or Ro 5-4864 was then reapplied. After a stable effect on the GABA response was achieved, both agonist and antagonist micropipettes were removed and control GABA responses were recorded. Data were accepted only if GABA responses evoked prior to and following benzodiazepine applications were equivalent.

Membrane potentials of dorsal root ganglion neurons were maintained at about $-60 \mathrm{mV}$, and $500 \mu \mathrm{s}$ depolarizing current pulses (frequency $4 \mathrm{~Hz}$ ) were used to evoke calcium-dependent action potentials. Blockade of voltage-dependent potassium conductances by extracellular TEA and intracellular injection of cesium ions enhanced the duration of the calcium component of the action potential so that it was 100-1000 times that of the sodium component. Following stabilization of action potential duration, benzodiazepines were applied by pressure ejection $(0.8$ psi, 3-5 s before the action potential was evoked. Data were accepted only if action potential duration returned to the control values within 2 min of removal of the drug-containing micropipette.

\section{RESULTS}

Diazepam ( $>1 \mathrm{nM}$ ) reversibly enhanced GABA responses of spinal cord neurons (Fig. 1A1) in a concentration-dependent manner, with $20 \%$ enhancement at $10 \mathrm{nM}$ and $80 \%$ enhancement at 100 nM (Fig. 2, filled circles). In contrast, Ro 5-4864 reversibly inhibited GABA responses (Fig. 1A2) in a concentration dependent manner, with $9 \%$ inhibition at $100 \mathrm{nM}, 24 \%$ inhibition at $1 \mu \mathrm{M}$ and $58 \%$ inhibition at $10 \mu \mathrm{M}$ (Fig. 2, filled squares). The benzodiazepine antagonist Ro 15-178811 $(1 \mu \mathrm{M})$ blocked the enhancement of GABA responses by diazepam $(100 \mathrm{nM})$ (Fig. 1B1), but Ro 15-1788 did not alter the inhibition of GABA responses by Ro 5-4864 (10 $\mu \mathrm{M})$ 


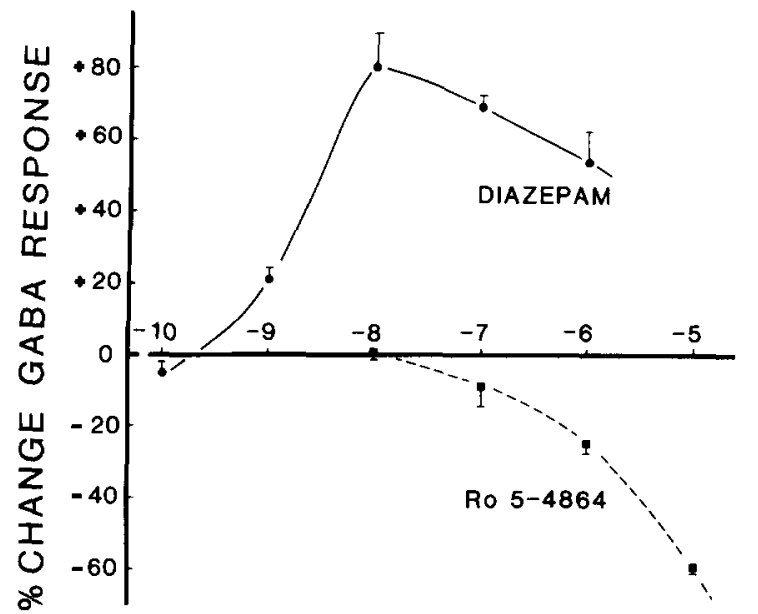

Fig. 2. Concentration-dependence of diazepam (circles) and Ro 5-4864 (squares) effects upon GABA responses of spinal cord neurons. Data shown are the means \pm S.E.M. of responses from 7 or more neurons for each drug and concentration tested. Benzodiazepine concentrations shown on the abscissa are logarithm molar.

(Fig. 1B2). Neither diazepam (1 $\mu \mathrm{M})$ (Fig. 1C1) nor Ro 5-4864 (10 $\mu \mathrm{M})$ (Fig. 1C2) altered responses of spinal cord neurons to S-glutamate (diazepam responses, $98.8 \pm 1.0 \%$ control, $\mathrm{n}=10$ neurons; $\mathrm{Ro}$ 5-4864 responses, $97.4 \pm 1.2 \%$ control, $\mathrm{n}=5$ neurons). Similarly, resting membrane potential and conductance were unaltered by diazepam $(0.1$ $\mathrm{nM}-10 \mu \mathrm{M})$ or Ro 5-4864 $(10 \mathrm{nM}-10 \mu \mathrm{M})$ in spinal cord neurons (KAc or $\mathrm{KCl}$ impalements) and in dorsal root ganglion neurons (CsAc impalements).

Injection of a depolarizing pulse of sufficient magnitude into spinal cord neurons elicits sustained, high frequency repetitive firing (see control cell, Fig. 3). Diazepam and Ro 5-4864 limited repetitive firing in a dose-dependent manner. At $87.5 \mathrm{nM}$, diazepam limited repetitive firing to one or a few action potentials in half the neurons tested, while 6 of 7 neurons were limited at $175 \mathrm{nM}$ diazepam (Fig. 3). Ro 5-4864 limited repetitive firing in 5 of 7 neurons at $500 \mathrm{nM}$ and 9 of 10 neurons at $10 \mu \mathrm{M}$.

Spontaneous activity of spinal cord neurons was limited by both diazepam and Ro 5-4864 (Figs. 4 and 5) with Ro 5-4864 being more potent, significantly inhibiting activity (reduction of activity grade, see Fig. 5) at $500 \mathrm{nM}$ and greater. Diazepam only significantly inhibited activity at $10 \mu \mathrm{M}$; at this concentration Ro 5-4864 produced quiescence in all 15 neurons studied. Action potentials could still be evoked in all quiescent neurons. In contrast, another GABA antagonist, picrotoxin, produced paroxysmal depolarizing events (grade 5 activity) at $100 \mu \mathrm{M}$ in each neuron.

Diazepam had insignificant effects on the duration of dorsal root ganglion neuron calcium-dependent action potentials at $100 \mathrm{nM}(94.4 \pm 2.1 \%$ control, 8 neurons) and at $1 \mu \mathrm{M}(93.8 \pm 2.6 \%$ control, 11 neurons) (Fig. 6). At $10 \mu \mathrm{M}$ diazepam shortened calcium-dependent action potential duration by $16.2 \pm$ $3.6 \%$ (11 neurons). Ro 5-4864 had only minor effects at $1 \mu \mathrm{M}(8.3 \pm 2.0 \%$ shortening, 6 neurons) while reducing calcium-dependent action potential duration by $24.6 \pm 2.6 \%$ at $10 \mu \mathrm{M}$ (10 neurons) (Fig. 6).

\section{DISCUSSION}

In the present study we have shown that diazepam enhanced but Ro 5-4864 depressed GABA responses while neither benzodiazepine modified glutamate responses. Diazepam presumably enhanced GABA responses by binding to high affinity benzodiazepine receptors, but at what receptors did Ro 5-4864 act to antagonize GABA responses? It is unlikely that Ro 5-4864 antagonized GABA responses by binding to the GABA recognition site since Ro 5-4864 has not

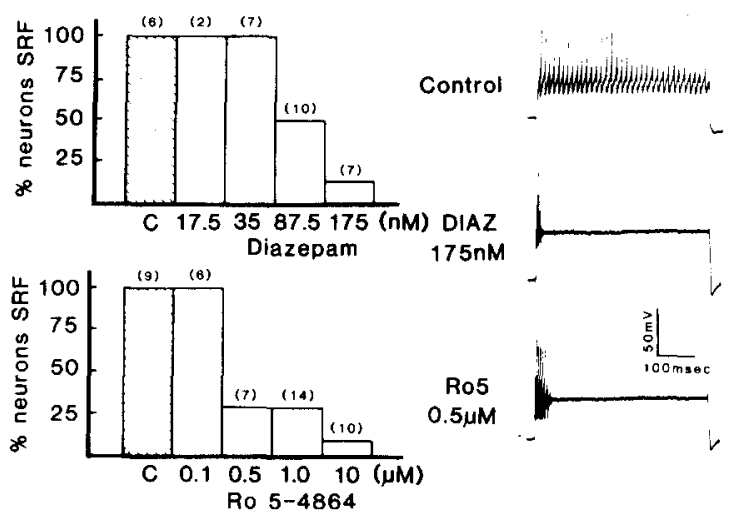

Fig. 3. Limitation of sustained, high frequency repetitive firing of spinal cord neurons by diazepam and Ro 5-4864. Data are expressed as \% of neurons exhibiting sustained, high frequency repetitive firing at each drug concentration (numbers of cells studied at each concentration shown in brackets). Control (drug free) cell populations are shown as hatched bars (C). Sample photographed oscilloscope traces are shown at right. These traces were recorded from neurons with resting membrane potentials of -60 to $-70 \mathrm{mV}$, which were stimulated with intracellular depolarizing current pulses of $1.5-2.0 \mathrm{nA}$ and 450 $\mathrm{ms}$ duration. The panels shows the greatest number of action potentials elicited by one of a series of depolarizing current pulses. 

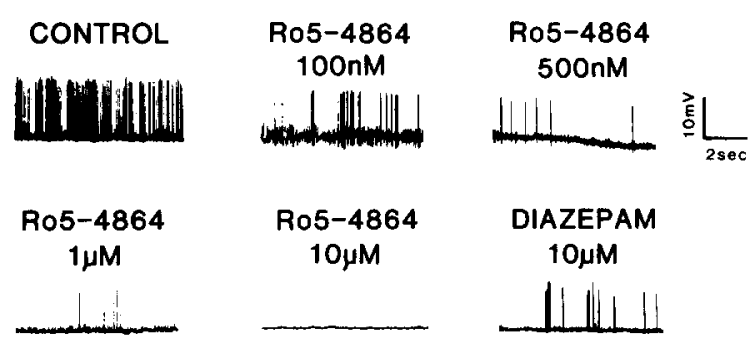

Fig. 4. Effects of diazepam and Ro 5-4864 on spontaneous activity of spinal cord neurons. Membrane potentials of cells were maintained at -55 to $-70 \mathrm{mV}$.

been shown to inhibit $\left[{ }^{3} \mathrm{H}\right] \mathrm{GABA}$ binding ${ }^{30}$. Furthermore, the effect of Ro 5-4864 is unlikely to be due to binding to high affinity benzodiazepine receptors since the effect was not influenced by the benzodiazepine antagonist Ro 15-1788. It is unlikely that Ro 5-4864 antagonized GABA responses by binding to the high affinity 'peripheral' type benzodiazepine receptor. The high affinity binding sites for Ro 5-4864 in brain and peripheral tissues have dissociation constants of 1-10 nM, while in the present studies, Ro 5-4864 had no effect on GABA responses below 100 $\mathrm{nM}$ although this concentration would almost fully saturate the high affinity Ro 5-4864 binding sites 27,32 . It has been suggested that the nanomolar Ro 5-4864 sites may be non-neuronal and located on glial cells since high densities of [ $\left.{ }^{3} \mathrm{H}\right] \mathrm{Ro} 5-4864$ binding sites were found on glial cell lines $8.18,30$ and striatal kainic

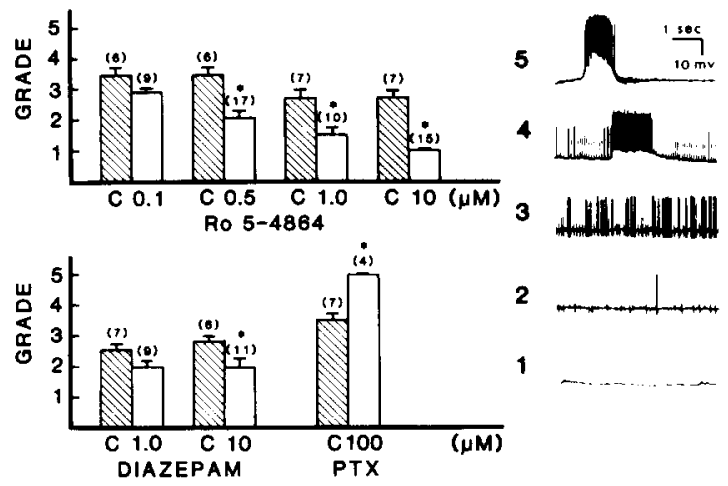

Fig. 5. Concentration-dependence of diazepam and Ro 5-4864 effects upon spontaneous activity of spinal cord neurons. Results with the convulsant GABA antagonist picrotoxin (PTX) are shown for comparison. Bars show mean grade \pm S.E.M. of activity, graded according to the scale shown at right (see ref. 19 for details). Control bars (C) are hatched. Numbers in parentheses represent the number of cells studied. Asterisks indicate a statistically significant difference from control grade ( $P$ $<0.05$, Student's $t$-test, 2-tailed).

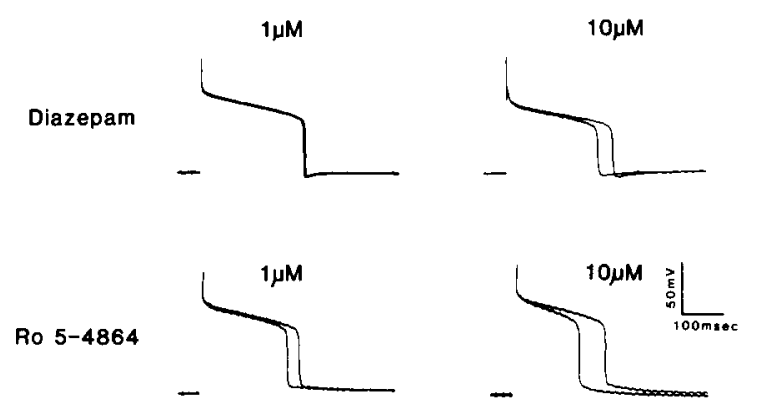

Fig. 6. Effects of diazepam and Ro 5-4864 upon calcium-dependent action potentials in dorsal root ganglion neurons. Retouched oscilloscope traces from representative cells are shown.

acid lesions, which produced marked glial proliferation, resulted in up to 10 -fold increases in $\left[{ }^{3} \mathrm{H}\right] \mathrm{Ro}$ 5-4864 binding27. Ro 5-4864 has been shown to also interact with a lower (micromolar) affinity site in synaptosomal membranes ${ }^{1,27,32}$ and recently, autoradiographic techniques have revealed a lower affinity, low density $\left[{ }^{3} \mathrm{H}\right] \mathrm{Ro} 5-4864$ binding site in brain sections ${ }^{21}$. The results of the present study suggest that Ro 5-4864 receptors on spinal cord neurons are of apparent micromolar affinity and are, at least in part, negatively coupled to GABA receptors. In these respects, Ro 5-4864 actions are likely distinct from those of the inverse agonist DMCM (methyl 6,7-dimethexy-4-ethyl- $\beta$-carboline-3-carboxylate) which is a potent inhibitor of benzodiazepine binding and also inhibits GABA responses ${ }^{2}$. It is of interest that maximal enhancement of GABA responses was produced at about $10 \mathrm{nM}$ and that higher diazepam concentrations produced less enhancement. It is possible that the reduction of diazepam enhancement at high nanomolar concentrations is due also to an interaction with the low affinity receptor.

These results may explain some of the differing behavioral actions of the two benzodiazepines. Concentrations of diazepam with activity against anxiety and generalized absence seizures in man and PTZ seizures in mice are likely to be low nanomolar in the cerebrospinal fluid 12 . Thus, diazepam may have anxiolytic and anti-PTZ seizure activity because it enhances GABAergic inhibition. In contrast, Ro 5-4864 has no anti-PTZ activity and may be anxiogenic and convulsant because it antagonized postsynaptic GABAergic inhibition. These conclusions are supported by studies of non-benzodiazepine anticonvulsants and convulsants. Barbiturates, which are an- 
tagonists of PTZ seizures, also enhance GABA responses ${ }^{17,22,29}$, while phenytoin and carbamazepine, which are inactive against PTZ seizures, do not enhance GABA responses at therapeutic concentrations ${ }^{14,19}$. Furthermore, compounds such as bicuculline, picrotoxin, PTZ and penicillin, which antagonize GABA responses ${ }^{16}$, are convulsants.

We have also shown that diazepam and Ro 5-4864 limit sustained, high frequency repetitive firing. However, diazepam was less potent in limiting repetitive firing than in enhancing GABA responses and has been shown to be less potent against MES seizures than against PTZ seizures ${ }^{36}$. Other studies have demonstrated that drugs with activity against MES seizures (e.g. phenytoin and carbamazepine) limit sustained, high frequency repetitive firing of spinal cord neurons in cell culture at therapeutic cerebrospinal fluid concentrations ${ }^{19,20}$. Thus, it is possible that diazepam has anti-MES seizure activity, at least in part, due to its ability to limit sustained, high frequency repetitive firing. Ro 5-4864 also limited sustained, high frequency repetitive firing. However, it is not clear that Ro 5-4864 has anti-MES seizure activity at non-convulsive doses $6,24,35,36$. This may be due to the overlapping dose dependencies of Ro 5-4864 action on GABA responses and repetitive firing. Ro 5-4864 inhibited GABA responses at $100 \mathrm{nM}$ while reducing repetitive firing only above $100 \mathrm{nM}$. Thus, convulsant action may occur at concentrations below those required for anticonvulsant action.

In the present study, we have shown also that Ro 5-4864 and diazepam decreased calcium-dependent action potential duration in dorsal root ganglion neurons and spontaneous activity in spinal cord neurons, but that Ro 5-4864 was more potent. Calcium-dependent action potential shortening and reduction of spontaneous activity both were produced by Ro $5-4864$ at or above $500 \mathrm{nM}$ but by diazepam at or above $10 \mu \mathrm{M}$. Nanomolar concentrations of diazepam have been shown to enhance potassium stimulated calcium uptake ${ }^{23}$, but $100 \mathrm{nM}$ diazepam had little effect on calcium-dependent action potential duration in the present experiments. Micromolar

\section{REFERENCES}

1 Bowling, A. C. and DeLorenzo, R. J., Micromolar affinity benzodiazepine receptors; identification and characterization in the central nervous system, Science, 216 (1982) concentrations of Ro 5-4864, diazepam and other benzodiazepines have been shown also to inhibit calcium uptake by synaptosomes ${ }^{13,34}$. It is possible that the benzodiazepines reduce calcium entry and thus decrease release of neurotransmitter which results in depression of spontaneous firing. Similar results have been described for barbiturates and phenytoin ${ }^{10,19}$. Thus, Ro 5-4864 and diazepam may have sedative action, at least in part, due to reduction of presynaptic calcium entry and release of neurotransmitter. Diazepam, however, might be non-sedative at low doses due to the large separation between concentrations effective in enhancing GABA responses and reducing calcium entry.

In conclusion, the effect of $p$-chloro substitution on diazepam not only markedly altered the neurochemical and behavioral activity of the resultant compound, Ro 5-4864, but also changed, relative to diazepam, its electrophysiological actions on neurons in vitro. Further, some correlation may be drawn between the convulsant, anticonvulsant and sedative actions of Ro 5-4864 and its actions in cultured spinal cord neurons. While Ro 5-4864 would have too many dangerous side-effects to be clinically useful as an anticonvulsant, it is possible that other benzodiazepines may have selective action against MES seizures without antagonizing GABAergic inhibition and thus have potential clinical application.

\section{ACKNOWLEDGEMENTS}

We would like to thank Ms. Debbie DeSmyther for secretarial assistance in preparing the manuscript. We are grateful to Hoffman-LaRoche, Nutley, NJ for gifts of Ro 5-4864 and diazepam, and acknowledge the helpful advice of Dr. B. A. Weissman. J.H.S. is a recipient of an award from the Rotary Foundation of Rotary International, and the research was funded by NIH Grants NS 19692 and NS 00408 to R.L.M. M.J.M was supported by Teacher-Investigator Development Award NS 00817 from the U.S. Public Health Service.

1247-1249.

2 Braestrup, C., Schmiechen, R., Neef, G., Nielsen, M. and Petersen, E. N., Interaction of convulsive ligands with benzodiazepine receptors, Science, 216 (1982) 1241-1243.

3 Choi, D. W., Farb, D. H. and Fishbach, G. D., Chlordiaze- 
poxide selectively augments GABA action in spinal cord cell cultures, Nature (Lond.), 269 (1977) 342-344.

4 DelZompo, M., Post, R. M. and Tallman, J. F., Properties of two benzodiazepine binding sites in spinal cord, Neuropharmacology, 22 (1983) 115-118.

5 File, S. E. and Lister, R. G., The anxiogenic action of Ro $5-4864$ is reversed by phenytoin, Neurosci. Lett., 35 (1983) 93-96.

6 File, S. E. and Mabutt, P. S., Behavioural effects of Ro 5-4864, a ligand for the 'micromolar benzodiazepine receptor', Brit. J. Pharmacol., 79 (1983) 76P.

7 File, S. E. and Pellow, S., Ro 5-4864, a ligand for benzodiazepine micromolar and peripheral binding sites: antagonism and enhancement of behavioural effects, Psychopharmacology, 80 (1983) 166-170.

8 Gallager, D. W., Mallorga, P., Oertel, W., Henneherry, R. and Tallman, J., $\left[{ }^{3} \mathrm{H}\right]$-Diazepam binding in mammalian central nervous system: a pharmacological characterization, J. Neurosci., 1 (1981) 218-255.

9 Haefely, W., Pieri, L., Polc, P. and Schaffner, R., General pharmacology and neuropharmacology of benzodiazepine derivatives, Handb. exp. Pharmacol., 55 (1981) 13-283.

10 Heyer, E. J. and Macdonald, R. L., Barbiturate reduction of calcium-dependent action potentials, Brain Research, 236 (1982) 157-171.

11 Hunkeler, W., Mohler, M., Pieri, L., Dole, P., Bonetti, E. P., Cumin, R., Schaffner, R. and Haefely, W., Selective antagonists of benzodiazepines, Nature (Lond.), 290 (1981) 514-516.

12 Kanto, J., Kangas, L. and Sirrotola, T., Cerebrospinal-fluid concentrations of diazepam and its metabolites in man, Acta pharmacol. Toxicol., 36 (1975) 328.

13 Leslie, S. W., Friedman, M. B. and Coleman, R. R., Effects of chlordiazepoxide on depolarization-induced calcium influx into synaptosomes, Biochem. Pharmacol., 29 (1980) 2439-2443.

14 Macdonald, R. L., Mechanisms of anticonvulsant drug action. Recent Advances in Epilepsy, Vol. 1, Churchill Livingstone, Edinburgh, London, Melbourne, New York, 1983, pp. 1-23.

15 Macdonald, R. L. and Barker, J. L., Benzodiazepines specifically modulate GABA-mediated postsynaptic inhibition in cultured mammalian neurons, Nature (Lond.), 271 (1978) 563-564.

16 Macdonald, R. L. and Barker, J. L., Specific antagonism of GABA-mediated postsynaptic inhibition in cultured mammalian spinal cord neurons: a common mode of convulsant action, Neurology, 28 (1978) 325-330.

17 Macdonald, R. L. and Barker, J. L., Enhancement of GABA-mediated postsynaptic inhibition in cultured mammalian spinal cord neurons: a common mode of anticonvulsant action, Brain Research, 167 (1979) 323-336.

18 McCarthy, K. D. and Harden, T. K., Identification of two benzodiazepine binding sites on cells cultured from rat cerebral cortex, J. Pharmacol. exp. Ther., 216 (1981) 183-191.

19 McLean, M. J. and Macdonald, R. L., Multiple actions of phenytoin on mouse spinal cord neurons in cell culture, $J$. Pharmacol. exp. Ther., 227 (1983) 779-789.

20 McLean, M. J. and Macdonald, R. L., Phenytoin and carbamazepine selectively limit sustained high frequency re- petitive firing of cultured mouse neurons, Soc. Neurosci. Abstr., 9 (1983) 398.

21 Mohler, M. and Richards, J. G., Autoradiographic visualization and pharmacological characterization of $\left[{ }^{3} \mathrm{H}\right]-\mathrm{Ro}$ 5-4864 binding in the CNS, Brit. J. Pharmacol., 79 (1983) 280.

22 Nicoll, R. A., Pentobarbital: action of frog motoneurons, Brain Research, 96 (1975) 119-123.

23 Paul, S. M., Luu, M. D. and Skolnick, P., The effects of benzodiazepines on presynaptic calcium transport. In $\mathrm{E}$. Usdin, P. Skolnick, J. F. Tallman, D. Greenblatt and S. M. Paul (Eds.), Pharmacology of Benzodiazepines, Macmillan, New York, 1983, pp. 87-92.

24 Pieri, L., Polc, P., Bonetti, E. P., Burkard, W., Cumin, R. and Haefely, W., Some pharmacological effects of Ro 5-4864, a specific ligand of the peripheral type of benzodiazepine binding sites, Naunyn-Schmiedeberg's Arch. Pharmacol., 322 (1983) R95.

25 Randall, L. O., Schallek, W., Sternback, L. M. and Ning, R. Y., Chemistry and pharmacology of the 1,4-benzodiazepines. In M. Gordon (Ed.), Psychopharmacological Agents, Vol. III, Academic Press, New York, 1976, pp. 175-281.

26 Ransom, B. R., Neale, E., Henkart, M., Bullock, P. N. and Nelson, P. G., Mouse spinal cord cells in culture. I. Morphologic and intrinsic neuronal electrophysiological properties, J. Neurophysiol., 40 (1977) 1132-1150.

27 Schoemaker, M., Morelli, M., Deshmukh, P. D. and Yamamura, H. I., $\left[{ }^{3} \mathrm{H}\right]$ Ro 5-4864 benzodiazepine binding in the kainate lesioned striatum and Huntington's diseased basal ganglia, Brain Research, 248 (1982) 396-401.

28 Schoemaker, H., Boles, R. G., Horst, W. D. and Yamamura, H. I., Specific high-affinity binding sites for $\left[{ }^{3} \mathrm{H}\right]-\mathrm{Ro} 5$ 4864 in rat brain and kidney, J. Pharm. exp. Ther., 225 (1983) 61-69.

29 Schulz, D. W. and Macdonald, R. L., Barbiturate enhancement of GABA-mediated inhibition and activation of chloride ion conductance: correlation with anticonvulsant and anesthetic actions, Brain Research, 209 (1981) $177-188$.

30 Sher, P. K., Schrier, B. K. and Van Putten, D., An in situ assay for determination of benzodiazepine binding, Develop. Neurosci., 5 (1982) 271-277.

31 Skerritt, J. H. and Johnston, G. A. R., Enhancement of GABA binding by benzodiazepines and related anxiolytics, Europ. J. Pharmacol., 89 (1983) 193-198.

32 Skerritt, J. H., Chen Chow, S., Johnston, G. A. R. and Davies, L. P., Purines interact with 'central' but not 'peripheral' benzodiazepine binding sites, Neurosci. Lett., 34 (1982) 63-68.

33 Squires, R. F. and Braestrup, C., Benzodiazepine receptors in rat brain, Nature (Lond.), 266 (1977) 732-734.

34 Taft, W. C. and DeLorenzo, R. J., Benzodiazepine inhibition of depolarization-induced synaptosomal Ca uptake. Proc. Amer. Soc. Neurochem., (1983) 195.

35 Weissman, B. A., Cott, J., Paul, S. M. and Skolnick, P., Ro 5-4864: a potent benzodiazepine convulsant, Europ. J. Pharmacol., 90 (1983) 149-150.

36 Zbinden, G. and Randall, L. O., Pharmacology of benzodiazepines: laboratory and clinical correlations, Advanc. Pharmacol., 5 (1967) 213-291. 